\title{
The Role of Environmental Factors in the Investment Prioritization of Facilities Using Recycled PVC
}

\author{
Ugur Bac* \\ Department of Industrial Engineering, Atilim University, Ankara, Turkey
}

Received: 17 September 2020

Accepted: 18 November 2020

\begin{abstract}
There are many types of solid wastes however, plastic wastes are among the ones which have several harmful effects on the environment. Plastic wastes have a long decomposition time in nature and the dangerous chemical compounds in them make them a threat for the environment along with other types of waste. Contamination caused by the plastic wastes attracts worldwide attention nowadays. As a member of thermoplastic polymers family, polyvinyl chloride (PVC) products are one of the most preferred type of plastic composition, which holds an important ratio in the total plastic waste amount. PVC wastes should either be disposed or recycled to minimize their harmful effects on the environment. The disposal approach is easy and cheap, but recycling alternative requires the investment on special facilities hence, a more expensive solution. However, disposal alternatives, such as landfilling and incineration, may also cause pollution due to high chlorine content of PVC; whereas, mechanical and chemical recycling options reduce many environmental problems. There is a clear tradeoff in the decision of handling PVC waste between the costs and environmental effects. The purpose of this study is to evaluate the factors considered during the investment decisions of PVC manufacturers to find out the importance of environmental factors by using a multi-criteria group decision making method.
\end{abstract}

Keywords: polyvinyl chloride, recycling, solid waste management, multi-criteria group decision making, plastic waste

\section{Introduction}

Plastic has a wide application area in daily life from construction sector to consumer goods. Plastic based products are being mass produced since 1950s and the rate of production increases exponentially ever since. Therefore, plastic wastes have an important share

*e-mail: ugur.bac@atilim.edu.tr among the solid wastes [1]. Considering life of plastic products, their long decomposition times, and their harmful chemical contents it can be said that amount of plastic waste has recently become a serious problem for the environment [2]. This makes handling of plastic wastes an important part of solid waste management (SWM) policies. Hence, plastic waste recycling gained more importance and rates of recycle increased to $18 \%$ from zero in the last thirty-five years, it is still at very low levels [3]. In 2018, 359 million tonnes (Mt) 
of plastic manufactured in the world, of which 61.8 Mt were produced in Europe [4]. 29.1 Mt of plastic waste was collected in Europe in 2018, which indicates an increase of $19 \%$ when compared to the amount collected in 2006; but only $32.5 \%$ of this waste was used for recycling [4]. Even the European Union's Waste Framework Directive (2008/98/EC) prioritizes recycling [5], incineration (with a rate of $42.6 \%$ ) is still preferred over recycling in Europe. Plastic wastes, which are not recycled, are posing a potential risk of toxicity for the environment [6], which recently resulted with a global plastic waste crisis caused by micro plastic wastes [7]. Plastic family consists of wide range of polymer types, and PVC products has $19 \%$ of the total demand in this group [8].

Polyvinyl chloride (PVC) is a type of thermoplastic material which has gained much attention lately because of its wide area of usage in daily life applications [9]. $\mathrm{PVC}$ is a member of polymer type plastics, which holds about $60 \%$ of total plastic use in major appliances in Europe [10]. PVC replaces metals, wood, paper and many other materials in products such as pipes, channels, window frames, cables, flooring and wall panels [11]. Especially, PVC pipes have been gradually replacing traditional copper pipes in significant applications with their advanced features. They are light, work under different pressures, easy to install, have low frictional loss, and low maintenance costs. Recently, PVC pipes are being used in many fields such as city water supply, for water well schemes, and spray irrigation systems. $60 \%$ of PVC manufactured in Turkey is being used for piping and other construction elements [12]. Recycled PVC can be used in the manufacturing of pipes that meets the current standards [13]. Life Cycle Assessment (LCA) results of using $\mathrm{PVC}$ in the manufacturing of pipes shows that the usage of PVC consumes less energy and also recycling PVC during manufacturing proved to have less environmental load when compared to other types of materials [14]. Moreover, Green PVC approach can be applied in facilities by means of using their wastes in closed-loop supply chains of their organizations [15]. PVC has many good qualities like its long life, chemical properties, ability to take different complex shapes, and ability to resist deformation under load [16]. PVC's thermal stability can also be improved by internal plasticizing process if required [17].

Different types of chemicals and additives are being used as stabilizers, plasticizers, or other purposes during the production of PVC, which makes wastes related with this product very harmful for the environment [10]. PVC waste includes more dioxin and furan formations than any other plastic waste [18]. Dioxin formation should be strictly controlled while applied in industry as well as in waste gasificationcombustion process [19]. Because of the high amount of chlorine included in PVC, incinerating to dispose of the waste, without using a proper flue gas treatment or state of the art incinerators, releases dioxin and other harmful pollutants [20]. Therefore, use of latest flue gas treatment technologies or state of the art incinerators prevents release of most harmful substances and they are highly suggested for incinerating option, especially for the developing countries where incineration is being applied mostly without using a proper filtration system. Unlike biodegradable plastic components which have less environmental effects on the soil [21], landfilling option for PVC disposal is also not an efficient option. Landfilling option for disposal has a drawback of land occupancy, which may be a problem for some countries [22], considering the long decomposition time of PVC products. Disposal methods have various effects on the environment such as; generating toxic gases, fumes, dust [23], pollutants for soil and underground resources [24], and flood occurrences, in addition to spreading diseases resulting in health deterioration and accidents in waste sites [25]. One of the main qualities of PVC is that its waste is recyclable [15]. Instead of disposal, recycling the PVC waste is much more preferable option for the environmental sustainability [11]. When compared with other plastic wastes, PVC also promises higher rate of recycling potential with a $79 \%$ [26]. However, recycling of PVC is more expensive, complicated and risky process when compared with other plastic wastes [27], which keeps recycling ratio of PVC waste at very low levels and leaves the environment vulnerable to its harmful effects. Even though, necessary regulations, directives and policies have been completed in macro level by many countries to encourage the recycling, actual recycle rate achieved still does not meet expectations.

To determine the reasons behind low preference rate of recycling, micro level studies should be conducted at facility level to comprehend the approaches of executives to recycling and environmental issues while taking decisions regarding investments. This issue is neglected in the literature. However, private sector plays an important role in the PVC industry, and company level management strategies should be understood well to be able to encourage the use of recycled plastic. The life of PVC products is around 50 years and the amount of PVC waste will increase exponentially in the near future because of this reason [28]. Therefore, it is essential to take necessary incentive measures to increase the rate of recycling of $\mathrm{PCV}$ waste by encouraging PVC manufacturers to use recycled input, even investing in recycling machinery and technology in their facilities by purchasing separated PVC waste [15], to reduce harmful impact on the environment [14]. This approach would aid municipals and governments during SWM related decisions.

In this study, a decision model is developed to analyze the investment decision priorities of PVC manufacturers in Turkey. The proposed model consists of several management performance evaluation criteria. The main aim is to find weights assigned to each criterion by the executive officers of PVC manufacturer facilities to understand their priorities while conducting their business. The structure of the model consists 
different criteria related with different aspects of companies' strategic management decisions. Variety of conflicting criteria should be satisfied simultaneously by the decisions taken by the management. Making some complex evaluations is necessary during such decisions to optimize the budget amount spent on investment alternatives. As being one of the main criteria, environmental factors should also be considered during the investment decisions. In decision models that consist variety of metrics, it is common to neglect some criteria unintentionally while making decisions. Therefore, using a multi-criteria group decision making (MCGDM) model for strategic level investment evaluations is an effective approach, hence there are several studies in the literature [29-31] that used multi-criteria decision making (MCDM) methods to evaluate different SWM strategies accurately.

\section{Methodology}

Most PVC products are manufactured from recycled waste in Europe [11]. It is an effective way since using recycled PVC disposes of wastes and reduces the environmental pollution at the same time. This approach also satisfies the requirements of zero-waste manufacturing and helps to achieve a sustainable circular economy model [32]. Turkey is also among countries to make a transition to zero-waste manufacturing in 2025 [12]. Increasing PVC recycling rate is a good fit for this purpose. PVC waste can be recycled by mechanical or chemical processes [33]. Mechanical recycling also reduces $\mathrm{CO}_{2}$ emissions during production by $30 \%$ when compared to production of virgin plastics [34] as long as the distance between the recycle facility and production facility is not so far [35]. When compared to mechanical recycling, chemical recycling is a more expensive technique, but this method reduces harmful effects to environment even more [11]. However, in most developing countries landfilling and incinerating methods are primarily preferred approaches in SWM disposal decisions [36]; whereas, recycling should be prioritized by governments considering the longterm benefits [37]. The aforementioned favorable properties of recycling are still not enough to increase the application rate of this method in Turkey [29]. Understanding reasons behind this requires evaluation of companies and their priorities in strategic decisions. It is important to balance economic growth with environmental progress in developing countries such as Turkey [25].

The purpose of this study is to propose a MCGDM framework to evaluate the importance of performance metrics in PVC companies to identify the relevant importance of environmental metrics during the investment decisions made by executives of PVC factories. Thus, reasons behind low recycling rate and other factors that excel them can be understood more clearly. To this aim, first, related criteria are determined with literature survey and interviews conducted with executives of PVC manufacturer facilities in which there is a usage of recycled PVC waste. Then, these experts evaluated each performance metric for MCDM analysis. Results of the proposed model clearly states which criteria are considered as the most important factors, and ranking of environmental issues among these factors in recycled PVC using facilities during important investment decisions. By doing so, future incentive measures can be taken to increase the importance of environmental factors in investment decisions to encourage the use of recycled PVC in more facilities.

\section{Determination of Evaluation Criteria}

Over the last few years a large number of studies have been published to acknowledge the dynamics of key performance measures as an effective tool for monitoring and evaluating business performance. To find out the gap between planning and implementation for a company, continuous monitoring of performance should be done by developing a set of key performance indicators (KPIs). This is not an easy job, and companies should concentrate on small number of KPIs which are very important for their finance, customers and operations management [38]. To identify root causes of problems and to control the service delivery in an organization, a right classification of KPIs is necessary. Hence, they can be classified by delivery type, e.g. maintenance and logistics or by performance dimension, e.g. cost, quality and time [39]. Quality, delivery, customer services, time measures, utilization of resources, costs and flexibility can be used to build a framework to measure performance of companies, and companies' executives need to choose the number of KPIs that are linked to the business strategy [40]. Even some studies claim that the cost, time and quality are more noticeable criteria to evaluate company's performance, other studies reveal that the successful companies are using more complex key performance indicators. Key issue on that matter is the validity of KPIs. Initial KPIs need to be evaluated by experts to make sure of that they are right for the specific sector in which their company operates [41]. KPIs can be divided into subjective and objective categories. Subjective indicators include quality, functionality, and customer satisfaction; whereas objective ones contain costs, time, rate of accidents and environmental impacts [42]. Some studies claim that, it is not an easy task to monitor KPIs for a company in real time and this could be expensive; therefore, KPIs must have a standardized characteristic [43].

Lindberg, Tan, Yan, and Starfelt claim that the energy, raw material, operation, planning, maintenance, equipment, and the inventory KPIs are the most popular metrics that can be used to evaluate the performance of an entire organization. This study also revealed that the high amount of waste is one of the main reasons 
for low performance [44]. In sustainable manufacturing there is always a need to evaluate the performance of organization by choosing the right KPIs to minimize the impact to the environment, since production process is a significant source of environmental impact. Amrina and Yusof developed forty one initial indicators which cover the economic, social, and environmental aspects of sustainable manufacturing [45]. New KPIs are usually being applied in sustainable manufacturing evaluations, such as land utilization, energy consumption, accident rates, air emissions, [46], preventing waste, and LCA related factors such as the usage rate of nonrenewable energy [47] are popular among companies which adapts sustainable practices. Environmental performance evaluation is very important for organizations in many countries to minimize the influence to the environment and keep companies' sustainable competition power in the market. To evaluate the environmental performance of companies, assessment of necessary KPIs, such as energy consumption, total waste, air emissions and waste quantities should be included in performance evaluation models [48]. Evaluation of the amount of total waste produced is especially important for PVC manufacturers considering its recyclable properties. During the manufacturing process of PVC pipes, at several stages, waste is produced during suspension and powder degassing at intensive mixers, extrusion process, disposal of non-complied fittings, extrusion purge, and because of chips from pipe sawing [15]. In addition to outsourced PVC waste, these internal wastes can also be used in manufacturing. From the aspect of SWM applications, it is more desired to use plastic wastes at the point of origin, since emissions generated during transportation may exceed the amount of reduced emissions by the recycling if the distances are too far between the production facility and waste separation facility [35]. Therefore, the amount of waste in PVC facilities should be an important metric to focus on considering cost savings and future investment plans.

Life Cycle Assessment (LCA) is another scientific approach being used for evaluating environmental impact of PVC products throughout their life cycle [49]. According to ISO 14040 standard [50], LCA approach has four steps: definition of the goal and scope of the study; data collection related with life cycle inventory (LCI); life cycle impact assessment (LCIA) using environmental indicators; and interpretation and analysis of the results. Environmental impact analyses are based mainly on several indicators related with energy consumption, resource consumption and pollutant discharge categories according to the subject of the assessment [51]. Most common impacts considered in the literature are abiotic resource depletion (ADP), acidification potential (AP), eutrophication potential (EP), fresh water aquatic ecotoxicity potential (FAETP), global warming potential (GWP), marine aquatic eco-toxicity potential (MAETP), ozone layer depletion potential (ODP), photochemical ozone creation potential (POCP), terrestrial ecotoxicity potential (TETP) [52], non-renewable energy use (NREU) [53], and waste production [54]. In LCA studies greenhouse gases (GHGs) that affects global warming are considered as $\mathrm{CO}_{2}, \mathrm{CH}_{4}, \mathrm{~N}_{2} \mathrm{O}$; and main gases that affects rain acidification are considered as $\mathrm{SO}_{2}, \mathrm{NO}_{x}, \mathrm{HCl}, \mathrm{H}_{2} \mathrm{~S}$, and $\mathrm{HF}$ [55].

Total number and types of criteria should be limited in MCDM analysis to ensure the accuracy and efficiency of findings and the list of criteria should be determined with the experts who makes the pairwise comparisons according to their management decisions in their enterprises. Even though being a completely different methodology than LCA, some main environmental indicators can be used in MCDM analysis. For this purpose, PVC related LCA environmental indicators are discussed with the four executives of PVC manufacturer companies in four different cities in Turkey, who are selected as DMs in this study, and green energy usage rate, resource consumption (resources such as fresh water and fresh raw material), emissions and toxicity (air emissions that include GHGs which have a GWP, gases that affect AP, and FAETP), and waste production indicators stated as the only ones being considered in strategic level decisions made in their companies. At strategic level decisions taken by $\mathrm{C}$-level officers in board meetings, operational level analysis is not being made, however these indicators are evaluated as the groupings suggested by the DMs according to how they are considered in their enterprises.

Finally, regarding the investment decisions that have environmental effects, there are governmental legislations that the companies must follow. Any type of planned project must comply with these environmental laws and legislations [56]. Also, some incentives regulated by the government, such as tax reliefs that encourage environment friendly applications in companies [57], require the consideration of these factors during the evaluation of investment alternatives.

KPIs determined as a result of literature research were shared with the experts for the confirmation of their applicability in PVC facilities, and validated ones are categorized according to their types. Evaluation criteria used for the study of recycled PVC using facilities are given in their hierarchical structure in Table 1 with their codes.

Criteria listed to evaluate performance can be detailed more by introducing one more sublayer into the model, but that's not the point of this study. Hierarchical structure with sixteen subcriteria under three main criteria is an efficient framework to evaluate the role of environmental factors' importance in investment decisions for the plastics industry in Turkey.

\section{Analytical Hierarchy Process (AHP)}

AHP first introduced by Saaty and it is being used as a powerful decision making method ever since. Wide field of applicability makes this method popular 
Table 1. Performance evaluation criteria considered by PVC facilities during investments.

\begin{tabular}{|c|c|c|c|}
\hline Main Criteria & Subcriteria & Description & Reference \\
\hline \multirow{7}{*}{$\begin{array}{l}\text { Operational } \\
\qquad\left(C_{1}\right)\end{array}$} & $\begin{array}{l}\text { Quality } \\
\left(C_{11}\right)\end{array}$ & $\begin{array}{l}\text { performance, value, features, reliability and durability } \\
\text { of products and rate of rejected products. }\end{array}$ & {$[39,44,45]$} \\
\hline & $\begin{array}{l}\text { Time and efficiency } \\
\qquad\left(C_{12}\right)\end{array}$ & $\begin{array}{l}\text { manufacturing cycle time, rate of production, unit per labor } \\
\text { hour. }\end{array}$ & {$[39,41,43,59]$} \\
\hline & $\begin{array}{l}\text { Inventory } \\
\quad\left(C_{13}\right)\end{array}$ & $\begin{array}{l}\text { how well the inventories managed (stockouts, excess } \\
\text { inventories, etc.). }\end{array}$ & {$[38,44,46]$} \\
\hline & $\begin{array}{l}\text { Planning } \\
\left(C_{14}\right)\end{array}$ & $\begin{array}{l}\text { planning and scheduling impacts on how plant capacity is } \\
\text { utilized. }\end{array}$ & {$[38,43,44]$} \\
\hline & $\begin{array}{l}\text { Logistics } \\
\left(C_{15}\right) \\
\end{array}$ & $\begin{array}{l}\text { speed of the delivery, ability to use different distribution } \\
\text { channels. }\end{array}$ & {$[46,48,60]$} \\
\hline & $\begin{array}{c}\text { Equipment and main- } \\
\text { tenance } \\
\left(C_{16}\right) \\
\end{array}$ & $\begin{array}{l}\text { number of alarms rising in a certain time period, equipment } \\
\text { wears per month or per operation hours and vibration range for } \\
\text { machinery. }\end{array}$ & {$[43,44,48]$} \\
\hline & $\begin{array}{l}\text { Flexibility } \\
\qquad\left(C_{17}\right)\end{array}$ & $\begin{array}{l}\text { material quality, current technological level, speed to deliver } \\
\text { new products, speed to modify current products. }\end{array}$ & {$[45,59,61]$} \\
\hline \multirow{3}{*}{$\begin{array}{l}\text { Economic } \\
\qquad\left(C_{2}\right)\end{array}$} & $\begin{array}{l}\text { Costs } \\
\left(C_{21}\right)\end{array}$ & $\begin{array}{l}\text { manufacturing, service, material, and transportation costs over } \\
\text { a time period. }\end{array}$ & $\begin{array}{l}{[29,39,40,41,46,59} \\
60]\end{array}$ \\
\hline & $\begin{array}{l}\text { Energy consumption } \\
\qquad\left(C_{22}\right)\end{array}$ & $\mathrm{kwh} / \mathrm{month}$ for electricity or liter/month for fuel. & {$[44,46,62]$} \\
\hline & $\begin{array}{l}\text { Marketing } \\
\qquad\left(C_{23}\right)\end{array}$ & total amount spent on advertising per year. & {$[42,63]$} \\
\hline \multirow{6}{*}{$\begin{array}{l}\text { Environmental } \\
\qquad\left(C_{3}\right)\end{array}$} & $\begin{array}{c}\text { Waste } \\
\left(C_{31}\right) \\
\end{array}$ & solid waste, tons per month of material. & $\begin{array}{c}{[6,15,31,32,35,46,48} \\
51,54,62] \\
\end{array}$ \\
\hline & $\begin{array}{l}\text { Emissions and toxicity } \\
\qquad\left(C_{32}\right)\end{array}$ & $\begin{array}{l}\text { air emissions that include greenhouse gases which cause global } \\
\text { warming, gases that have acidification potential, fresh water } \\
\text { aquatic eco-toxicity potential, and pollution and contamination } \\
\text { on land caused by the plant operations over a time period. }\end{array}$ & $\begin{array}{c}{[11,29,31,34,35,46,47} \\
48,49,51,52,53-55,58]\end{array}$ \\
\hline & $\begin{array}{l}\text { Recycling } \\
\left(C_{33}\right)\end{array}$ & percent of recycled inputs used for production. & $\begin{array}{c}{[6,11,15,23,28,33-35} \\
37,49,52,53,58]\end{array}$ \\
\hline & $\begin{array}{l}\text { Green energy usage } \\
\left(C_{34}\right)\end{array}$ & the ratio of energy from green resources to total energy used. & {$[49,54,58]$} \\
\hline & $\begin{array}{c}\text { Resource consumption } \\
\left(C_{35}\right)\end{array}$ & resources such as fresh water and fresh raw material. & {$[49,51,52]$} \\
\hline & $\begin{array}{l}\text { Legislations and } \\
\text { incentives }\left(C_{36}\right)\end{array}$ & compliance with local legislations and incentives. & {$[56,57]$} \\
\hline
\end{tabular}

among researchers, and in more than $65 \%$ of studies AHP is preferred as a MCDM method [30]. AHP is an effective method to support complex decision problems that include conflicting and overlapping criteria. AHP utilizes pairwise comparisons between each criterion based on evaluations of experts. In this way, it turns problems into a hierarchical structure that gives a chance to decision makers (DMs) to make more accurate and efficient decisions by understanding the individual importance and effect of each criterion [64]. Therefore, AHP is a suitable method to define the role of environmental criteria in strategic decisions made in PVC facilities. AHP is basically implemented in three steps: First, the decision problem is organized in a hierarchical structure in terms of goals, criteria, sub-criteria, and if exists, alternatives. Next, pairwise comparisons of the criteria at each level is done by
DMs. Finally, synthesizing the decisions of hierarchy levels are done by considering the weights of each layer [65]. Alternative evaluation stage of the method is not used in this study, since main goal of the hierarchy is to determine the importance of each criterion, no alternatives introduced into the model. Also, types of criteria determined in this study have a clear structural and descriptive differences between them, which makes them suitable to be evaluated with AHP, and this property of criteria implies that there is no need for fuzzy logic applications during the evaluation phase. Saaty suggested a 9-point scale for the pairwise evaluations to rate the strength of the relationship between items (where 1: represents equal importance, 9: represents absolute importance; and reciprocals can also be used) [66]. Steps of AHP method are as follows: 
Step-1: Structure the hierarchy of the decision model. Repeat Steps 1-4 for main criteria and all subcriterion groups.

Step-2: Construct the pairwise comparison matrices for main criteria and each subcriteria layer by collecting $\mathrm{DM}$ evaluations in the following matrix form:

$$
\begin{gathered}
A^{k}=\left[a_{i j}^{k}\right]=\left[\begin{array}{cccc}
1 & a_{12}^{k} & \cdots & a_{1 n}^{k} \\
1 / a_{12}^{k} & 1 & \cdots & a_{2 n}^{k} \\
\vdots & \vdots & \ddots & \vdots \\
1 / a_{1 n}^{k} & 1 / a_{2 n}^{k} & \cdots & 1
\end{array}\right], \\
k=1, \ldots, l ; i=1, \ldots, n ; j=1, \ldots, n
\end{gathered}
$$

$a_{i j}{ }^{k}$ represents the relative importance of $i^{\text {th }}$ criterion to $j^{\text {th }}$ criterion assigned by DM $k$ [67]. This matrix is used to calculate the eigenvalues and the eigenvectors. In a decision model, all $l$ decision makers should fill a separate $A^{k}$ matrix that includes $n$ criteria for each criteria group (it is allowed to have different numbers of criteria under each criteria group, but since all calculations are being made separately for each group separation of indices is not required). Pairwise comparisons are done by using the 9-point scale with the comparison of two criteria (represented by $i$ an $j$ indices) one at a time and assigned to related $a_{i j}{ }^{k}$ cell.

Step-3: To examine the consistency of the pairwise comparison matrices $\left(A^{k}\right)$ filled by DM $k$, it is needed to compute the maximum eigenvalue $\left(\lambda^{k}{ }_{\max }\right)$ for $l \mathrm{DMs}$ separately by using Equation (2). Calculations of eigenvector $\left(W_{i}^{k}\right)$ for each $i^{\text {th }}$ criterion in the criteria group, and $W_{i}^{k}$ matrix for the same criteria group for all $l$ decision makers are needed prior to the calculation of $\lambda^{k}{ }_{\max } . W_{i}^{k}$ and $W^{k \prime}$ can be calculated with Equations (3) and (4) respectively.

$$
\begin{gathered}
\lambda_{\max }^{k}=\left(\frac{1}{n}\right)\left(\frac{W_{1}^{k \prime}}{W_{1}^{k}}+\cdots+\frac{W_{n}^{k \prime}}{W_{n}^{k}}\right), k=1, \ldots, l \\
W_{i}^{k}=\frac{\left[\prod_{j=1}^{n} a_{i j}^{k}\right]^{1 / n}}{\sum_{i=1}^{n}\left[\Pi_{j=1}^{n} a_{i j}^{k}\right]^{1 / n}}, k=1, \ldots, l ; i=1, \ldots, n \\
W^{k^{\prime}}=A^{k} \times W^{k}=\left[\begin{array}{cccc}
1 & a_{12}^{k} & \cdots & a_{1 n}^{k} \\
1 / a_{12}^{k} & 1 & \cdots & a_{2 n}^{k} \\
\vdots & \vdots & \ddots & \vdots \\
1 / a_{1 n}^{k} & 1 / a_{2 n}^{k} & \cdots & 1
\end{array}\right] \\
\times\left[\begin{array}{c}
W_{1}^{k} \\
W_{2}^{k} \\
\vdots \\
W_{n}^{k}
\end{array}\right]=\left[\begin{array}{c}
W_{1}^{k^{\prime}} \\
W_{2}^{k^{\prime}} \\
\vdots \\
W_{n}^{k^{\prime}}
\end{array}\right], k=1, \ldots, l
\end{gathered}
$$

$\lambda^{k}{ }_{\max }$ should be appropriate to the eigenvector for all DMs, so that they become the relative weight values in the evaluation criteria [68], which means that $W_{i}^{k}$ values can be used as the weight of criteria $i$ assigned by DM $k$. Consistency in the evaluations of $k^{\text {th }}$ decision maker is controlled in terms of the Consistency Index $\left(C I^{k}\right)$ and Consistency Ratio $\left(C R^{k}\right)$ calculated by Equations (5) and (6) respectively. A $C R^{k}$ value calculated less than 0.10 is acceptable as a consistent comparison. Random Consistency Index $(R I)$ value is a constant which is the result of large number of simulations. It differentiates according to the order of the $A^{k}$ matrix (in size of $n$ ) as stated by Saaty [69].

$$
\begin{gathered}
C I^{k}=\frac{\lambda_{\max }^{k}-n}{n-1}, k=1, \ldots, l \\
C R^{k}=\frac{C I^{k}}{R I}, k=1, \ldots, l
\end{gathered}
$$

Step-4: According to group decision making rules, $l$ amount of individual DM evaluations should be aggregated by using geometric mean to form the group decision matrices for each criteria group $\left(\bar{A}^{G}\right)$ separately by using Equation (7) for all $a_{i j}{ }^{k}$ values one at a time for all $l$ DMs to calculate each $\bar{a}_{i j}{ }^{i}$ member of the $\bar{A}^{G}$ [67]. After applying Step-3 for these aggregated group decision matrices for each criterion group and confirming the consistencies, $W_{i}$ values calculated for each $\bar{A}^{G}$ can be used as the final criteria weights for $n$ criteria in the related group decision matrix. $\bar{A}^{G}$ matrix, where $G$ index states the geomean aggregated element, has the same structure as the individual initial decision matrix given in Equation 1, only difference is there is a single aggregated decision matrix for each criteria group.

$$
\bar{a}_{i j}^{G}=\left(\prod_{k=1}^{l} a_{i j}^{k}\right)^{1 / l}, i=1, \ldots, n ; j=1, \ldots, n
$$

Step-5: Synthesize the results by aggregating the main and subcriteria weights to calculate the global criteria weights by simply multiplying the main criteria weights with the individual weight of the criterion.

\section{Determining Investment Priorities of PVC Manufacturers}

Evaluations of criteria are done by different DMs selected among PVC manufacturer companies' executives from four different industrial zones in Turkey. Companies selected are all using recycled PVC to some extend in their manufacturing operations

Table 2. Aggregated decision matrix for main criteria category layer and related AHP calculations.

\begin{tabular}{|c|c|c|c|c|}
\hline Main Criteria & $C_{1}$ & $C_{2}$ & $C_{3}$ & Weight $\left(W_{i}\right)$ \\
\hline$C_{1}$ & 1.00 & 0.39 & 1.32 & 0.228412 \\
\hline$C_{2}$ & 2.59 & 1.00 & 3.57 & 0.600649 \\
\hline$C_{3}$ & 0.76 & 0.28 & 1.00 & 0.170939 \\
\hline
\end{tabular}


Table 3. Aggregated decision matrix for operational criteria group and related AHP calculations.

\begin{tabular}{|c|c|c|c|c|c|c|c|c|}
\hline Operational Criteria & $C_{11}$ & $C_{12}$ & $C_{13}$ & $C_{14}$ & $C_{15}$ & $C_{16}$ & $C_{17}$ & Weight $\left(W_{i}\right)$ \\
\hline$C_{11}$ & 1.00 & 0.47 & 2.00 & 4.53 & 5.89 & 7.94 & 6.70 & 0.257932 \\
\hline$C_{12}$ & 2.11 & 1.00 & 4.09 & 5.01 & 6.48 & 8.24 & 8.45 & 0.378281 \\
\hline$C_{13}$ & 0.50 & 0.24 & 1.00 & 3.87 & 5.18 & 7.17 & 5.89 & 0.178905 \\
\hline$C_{14}$ & 0.22 & 0.20 & 0.26 & 1.00 & 2.06 & 3.50 & 3.13 & 0.075935 \\
\hline$C_{15}$ & 0.17 & 0.15 & 0.19 & 0.49 & 1.00 & 2.45 & 2.21 & 0.049756 \\
\hline$C_{16}$ & 0.13 & 0.12 & 0.14 & 0.29 & 0.41 & 1.00 & 0.50 & 0.025519 \\
\hline$C_{17}$ & 0.15 & 0.12 & 0.17 & 0.32 & 0.45 & 2.00 & 1.00 & 0.033672 \\
\hline
\end{tabular}

$\lambda_{\text {max }}=7.34, C I=0.06, R I=1.32, C R=0.04$

Table 4. Aggregated decision matrix for economic criteria group and related AHP calculations.

\begin{tabular}{|c|c|c|c|c|}
\hline Economic Criteria & $C_{21}$ & $C_{22}$ & $C_{23}$ & Weight $\left(W_{i}\right)$ \\
\hline$C_{21}$ & 1.00 & 1.57 & 3.50 & 0.506394 \\
\hline$C_{22}$ & 0.64 & 1.00 & 3.22 & 0.365517 \\
\hline$C_{23}$ & 0.29 & 0.31 & 1.00 & 0.128088 \\
\hline
\end{tabular}

$\lambda_{\max }=3.01, C I=0.01, R I=0.58, C R=0.01$

and some of them has a built-in recycling facility. Purpose of this selection is to shed light into the recycling experiences, and by doing so understanding the favorable and unfavorable aspects of recycling PVC in Turkish PVC manufacturers. Since Turkey is a developing country, results related with Turkey would also help readers to understand the importance of environmental factors in developing countries. Therefore, executives of these facilities from Istanbul, Izmir, Kocaeli, and Ankara filled individual pairwise comparison matrices. All these matrices checked oneby-one for $C R$ values to ensure consistency on the final aggregated decision matrix, and for all individual pairwise comparison matrix a $C R$ value of less than 0.10 is found. Next, for each decision level, related matrices have been aggregated by using Equation (7). Thereafter, consistency values were calculated again for the aggregated decision matrices to check consistencies. Finally, relative weights of each criteria group were calculated beginning with the main criteria group.

AHP calculations are firstly done for the main category layer. For this purpose, operational, economic, and environmental criteria are compared in pairs and relative importance scores between one and nine are assigned for each comparison by DMs according to scale suggested by Saaty [66]. Purpose of this comparison is to calculate the weight of each main criterion. After checking for inconsistencies final matrices of all DMs are merged with geometric mean. Resulting aggregated group decision matrix for the main criteria group is given in Table 2. $C R$ value of 0.00 suggests that the aggregated matrix is consistent. Considering the $C R$ values of individual decision matrices of each city $(0.00$, $0.00,0.03$, and 0.02) this was an expected result.

Next step of AHP method is the calculation of weights and $C R$ values for each subcriteria level. Steps of the AHP separately applied to all three subcriteria layers for the aggregated decision matrices of operational, economic, and environmental layers. Weights and $C R$ values found for each of these sublayers are given in Tables 3, 4, and 5 respectively. CR values corresponding to each aggregated subcriteria layer are $0.04,0.01$, and 0.04 , which validates the consistency of aggregated pairwise comparisons. $C R$ values of individual decision matrices of each city are $0.07,0.06$,

Table 5. Aggregated decision matrix for environmental criteria group and related AHP calculations.

\begin{tabular}{|c|c|c|c|c|c|c|c|}
\hline Environmental Criteria & $C_{31}$ & $C_{32}$ & $C_{33}$ & $C_{34}$ & $C_{35}$ & $C_{36}$ & Weight $\left(W_{i}\right)$ \\
\hline$C_{31}$ & 1.00 & 4.21 & 2.71 & 9.00 & 8.49 & 6.96 & 0.465624 \\
\hline$C_{32}$ & 0.24 & 1.00 & 0.37 & 3.66 & 3.22 & 1.86 & 0.121575 \\
\hline$C_{33}$ & 0.37 & 2.71 & 1.00 & 6.44 & 5.96 & 3.66 & 0.248527 \\
\hline$C_{34}$ & 0.11 & 0.27 & 0.16 & 1.00 & 0.58 & 0.21 & 0.031375 \\
\hline$C_{35}$ & 0.12 & 0.31 & 0.17 & 1.73 & 1.00 & 0.29 & 0.041665 \\
\hline$C_{36}$ & 0.14 & 0.54 & 0.27 & 4.79 & 3.41 & 1.00 & 0.091233 \\
\hline
\end{tabular}

$\lambda_{\text {max }}=6.24, C I=0.05, R I=1.24, C R=0.04$ 
$0.07,0.05$ for operational subcriteria; $0.03,0.05,0.02$, 0.00 for economic subcriteria; and $0.03,0.04,0.07,0.06$ for environmental subcriteria layer.

Aggregated group criteria weights are found as seen in Tables 2-5. Initial findings state that environmental criteria group has the least importance when compared with economic and operational KPI categories. Whereas, KPI representing the amount of waste came forward as the most important metric of environmental category. For the purpose of more detailed comparisons, it is better to inspect global criterion weights by aggregating main criteria layers' weights with subcriteria layers' weights by applying the Step -5 of the proposed MCGDM framework.

\section{Results and Discussion}

Individual weights of each main criterion and each subcriterion (calculated independent of main criteria weights) were already given in Tables 2-5 previously. Input data used for these calculations (aggregated pairwise comparison matrices) were also given in Tables 2-5. Output of these calculations are used as input data for the calculation of global criterion weights. According to Step-5, specific criterion level global weight calculations can be made by multiplying each criterion weight (weights given in Tables 3-5) with its main criteria category's weight (weights given in Table 2). For example, to calculate the global weight of each environmental subcriterion, individual weights of all environmental subcriteria $C_{31}(0.465624), C_{32}$
(0.121575), $C_{33}(0.248527), C_{34}(0.031375), C_{35}(0.041665)$ and $C_{36}(0.091233)$ are multiplied with the weight of environmental main criterion weight $C_{3}(0.170939)$ to acquire global weights of $C_{31}$ (0.079593), $C_{32}(0.020782)$, $C_{33}$ (0.042483), $C_{34}(0.005363), C_{35}(0.007122)$ and $C_{36}(0.015595)$, and finally all of them are converted to percentages $\left(C_{31}: 7.96 \%, C_{32}: 2.08 \%, C_{33}: 4.25 \%\right.$, $\left.C_{34}: 0.54 \%, C_{35}: 0.71 \%, C_{36}: 1.56 \%\right)$. Final global weights for all criteria are calculated and presented with their relative importance ranks in Table 6. All weights in Table 6 are represented in percentages with rounded two decimals for the ease of understanding and criteria are ranked according to their global weights.

Beginning with the main category comparisons, economic performance indicators are the most important criteria when executives are evaluating new investment alternatives or taking strategic level decisions, such as installing a recycling technology in their facilities or using recycled PVC as an input for the production. Economic aspect of investments, with a $60.06 \%$ global score, is 2.6 times more important than operational metrics (with a score of $22.84 \%$ ) and 3.5 times more important than environmental issues (with a score of $17.09 \%$ ) for PVC manufacturers in Turkey. This is an understandable fact in developing countries, considering the market conditions in private sector where there is a high competition between rivals and expensive prices of imported materials and technologies. Highly competitive market conditions force private sector companies to reduce manufacturing costs as much as possible and increase quality of their

Table 6. Summary of main criteria, subcriteria, and global importance rankings.

\begin{tabular}{|c|c|c|c|c|c|}
\hline Main Criteria & Weight (\%) & Subcriteria & Weight $(\%)$ & Global Weight (\%) & Ranking \\
\hline \multirow{7}{*}{ Operational $\left(C_{1}\right)$} & \multirow{7}{*}{$22.84 \%$} & Quality $\left(C_{11}\right)$ & $25.79 \%$ & $5.89 \%$ & 6 \\
\hline & & Time and efficiency $\left(C_{12}\right)$ & $37.83 \%$ & $8.64 \%$ & 3 \\
\hline & & Inventory $\left(C_{13}\right)$ & $17.89 \%$ & $4.09 \%$ & 8 \\
\hline & & Planning $\left(C_{14}\right)$ & $7.59 \%$ & $1.73 \%$ & 10 \\
\hline & & Logistics $\left(C_{15}\right)$ & $4.98 \%$ & $1.14 \%$ & 12 \\
\hline & & Equipment and maintenance $\left(C_{16}\right)$ & $2.55 \%$ & $0.58 \%$ & 15 \\
\hline & & Flexibility $\left(C_{17}\right)$ & $3.37 \%$ & $0.77 \%$ & 13 \\
\hline \multirow{3}{*}{ Economic $\left(C_{2}\right)$} & \multirow{3}{*}{$60.06 \%$} & Costs $\left(C_{21}\right)$ & $50.64 \%$ & $30.42 \%$ & 1 \\
\hline & & Energy consumption $\left(C_{22}\right)$ & $36.55 \%$ & $21.95 \%$ & 2 \\
\hline & & Marketing $\left(C_{23}\right)$ & $12.81 \%$ & $7.69 \%$ & 5 \\
\hline \multirow{6}{*}{$\begin{array}{l}\text { Environmental } \\
\qquad\left(C_{3}\right)\end{array}$} & \multirow{6}{*}{$17.09 \%$} & Waste $\left(\mathrm{C}_{31}\right)$ & $46.56 \%$ & $7.96 \%$ & 4 \\
\hline & & Emissions and toxicity $\left(\mathrm{C}_{32}\right)$ & $12.16 \%$ & $2.08 \%$ & 9 \\
\hline & & Recycling $\left(\mathrm{C}_{33}\right)$ & $24.85 \%$ & $4.25 \%$ & 7 \\
\hline & & Green energy usage $\left(C_{34}\right)$ & $3.14 \%$ & $0.54 \%$ & 16 \\
\hline & & Resource consumption $\left(C_{35}\right)$ & $4.17 \%$ & $0.71 \%$ & 14 \\
\hline & & Legislations and incentives $\left(C_{36}\right)$ & $9.12 \%$ & $1.56 \%$ & 11 \\
\hline
\end{tabular}


products if possible. Hence, costs criterion is found as the most important factor which is being considered in strategic level decisions. Therefore, it can be said that executives are focusing on taking economically feasible investment decisions, instead of considering environmental impacts of their decisions in Turkey. This management approach is common in most developing countries since these countries mainly rely on imported material, machines, equipment and manufacturing technologies. Factors like high levels of unemployment rate (about $16 \%$ in Turkey), high foreign depts (more than $\$ 430$ billion in Turkey), low income rates (minimum wage in Turkey is \$297/€252 for employed people), high inflation rates (at least 12\%/year), low profit margins, high tax rates, and constantly decreasing value of money because of unfavorable currency exchange rates are unfortunately bringing more urgent economic priorities to be considered in these countries. Especially pandemic caused by COVID-19 virus caused more damage in the economy because of the increase in the number of companies that went bankrupt during quarantine period.

However, examining the global weight of each criterion, results reveal more promising findings and provide a better understanding of the cause of indifference to environmental problems in Turkey. Amount of waste produced during manufacturing is ranked as the most important environmental subcriterion in its layer (with a score of $46.56 \%$ ), and fourth most important criterion in the whole model (with a global score of $7.96 \%$ ), which shows that there is an important need of reducing waste in PVC manufacturers. Actually, some of the waste produced can be recycled as raw material inside the facility if proper machinery and technology exist at the facility. In fact, recycling (which is the second most important subcriterion in environmental layer with $24.85 \%$ score) has the seventh rank (with $4.25 \%$ global score) among all sixteen criteria, which also makes it more important than half of other criteria. Actually, some strategies, suggested in the latest progress report published by Plastics Europe in 2019 about Operation Clean Sweep ${ }^{\circledR}$ [70] in accordance with the EU Strategy for Plastics in the Circular Economy [32], such as reducing all aspects of waste strategies by minimizing the pellet loss rate during logistics operations should be a cost-effective way of reducing waste amount. Application of these strategies would satisfy several criteria such as reducing costs and waste, and improving logistics performance simultaneously in Turkish companies. Despite these findings, environmental criteria group ranked last (with a $17.09 \%$ score in main criteria layer). More comparisons should be made between subcriteria global weights to understand the reasons behind this result.

Considering individual global weights in the environmental subcriteria group, waste and recycling subcriteria are actually important factors for executives of PVC companies in Turkey as being in the first half of all KPIs. However, in general these issues are being neglected mostly at the decision stage. Bearing in mind that costs are the most important subcriterion, it is understandable why recycling ranked seventh since it is a solution to reduce wastes and generate raw material input for the facility. Time and efficiency criterion ranked as third (with $8.64 \%$ global score) as a more important criterion than both waste and recycling; where quality criterion ranked sixth (with 5.89\% global score) as a more important criterion than recycling. These two factors' global importance rankings explain the lower importance of recycling when thought together with costs criterion. Firstly, using virgin polymer for production is much cheaper than recycling polymers in most cases, which is a disadvantage for recycling; especially if the facility doesn't have a builtin technology for that. Secondly, only one fifth of total plastic waste contains PVC, and this inhomogeneity makes recycling of $\mathrm{PVC}$ harder during the waste separation phase as confirmed by similar findings of studies in the literature $[8,11]$. Cross contamination is also a problem in Turkey [71], which can be another reason of low preference rate of recycling in PVC industry during investment prioritizations, since this problem affects both quality and time/efficiency criteria negatively. Finally, polymer compounds degrade after certain amount of recycling operations [6]. This unknown data about the background of PVC waste is also considered as another drawback regarding the quality related concerns.

Emissions and toxicity related issues, which is the third most important subcriterion in environmental layer with $12.16 \%$ score, have only about $2.08 \%$ effect in the overall decision process. Nineth ranking of the emissions and toxicity subcriterion can be explained by the current standards in the country supervised and controlled by the government. Executives are assuming that as long as their facilities satisfies the regulations there will not be any need to invest in new technologies to reduce emission values further to prevent environmental effects. In addition to previously discussed criteria, marketing (with $7.69 \%$ global weight) and inventory (with $4.09 \%$ global weight) criteria are more important to executives, since they are directly related with the production and sales efficiencies, which explains the general management philosophy clearly in developing countries such as Turkey. However, recycling PVC, instead of manufacturing it from the virgin raw materials, actually reduces total emissions [34]. At this point, some governmental policies are needed to reduce emissions and toxicity further to support recycling for the benefit of the environment in long term.

Legislations and incentives subcriterion, which was ranked fourth under environmental criteria layer with $9.12 \%$ score, ranked only eleventh according to its global score $(1.56 \%)$. This low importance can be explained with higher investment costs necessary to comply with the incentive opportunities, and considering break-even and rate of return analysis of required investments it can be said that current incentives do not appeal to PVC 
manufacturers Turkey. As mentioned before, strategies like cost effective waste reduction [70] should be encouraged by the government or local authorities by the introduction of necessary legislations and incentives in Turkey. Even though, obligation of founding a nonprofit producer responsibility organization (PRO) to deal with wastes and recycling in some European countries strategy [72] is not feasible for the economic structure of Turkey, the introduction of some measures to encourage other Extended Producer Responsibility (EPR) schemes to reduce wastes and boost recycling in manufacturers and in their value chains is a considerable field for incentives [73]. Additionally, landfilling and incineration restrictions and better use of taxation and other economic instruments to reward the uptake of recycling [74] would certainly increase the recycling rate in Turkey.

Resource consumption and green energy usage subcriteria are ranked last among the environmental group with scores of $4.17 \%$ and $3.14 \%$ respectively. These subcriteria also ranked at the end of the list, in fourteenth (with $0.71 \%$ global score) and sixteenth (with $0.54 \%$ global score) orders among all sixteen criteria. These results are not surprising in developing countries. Even most important environmental criteria, like emissions and toxicity, are being neglected in strategic level decisions as long as evaluated investment alternatives comply with legal regulations. Developing countries have a long way to catch on with the EU standards and rest of the developed countries' vision for environmental issues. Resource consumption is treated as a cost element in most of the companies in Turkey instead of an environmental issue, because of the lack of environmental awareness. The government should impose some legal sanctions in case of excessive resource consumption to increase awareness. Some policies may be regulated by local authorities to encourage the investment on green energy production facilities for larger companies, and additionally some tax incentives may be introduced for entrepreneurs who considers an investment in this field to increase renewable energy usage in Turkey, since current legislations do not seem effective enough for companies to consider these options.

Considering the results of this study, properties of PVC, and conclusions of other studies in the literature, it can be said that some external incentive measures are required for private sector PVC manufacturers to pay enough attention to environmental issues such as recycling, waste management, lower emissions, less resource consumption and more green energy usage in manufacturing. PVC manufacturers in Turkey found out to be aware about the environmental issues. However, competition in the market and economy of the country forces them to be more cost and time efficient in their productions with zero chance of quality defects. With the high investment cost requirements for recycling facilities, current technology related with the recycling of PVC, high contamination ratio of plastic wastes, challenging separation procedures, and cheaper price of virgin polymers with more promising final product quality are the main reasons for recycling to be less preferred alternative for the manufacturing and as an investment option in Turkey.

\section{Conclusions}

This study focuses on PVC product manufacturers in Turkey which also uses recycled PVC waste as an input. Main idea behind this study is to understand the importance of environmental issues in the strategic level investment decisions made by executives of these companies. Therefore, sixteen performance metrics collected from the literature survey used in a MCGDM model to calculate the global importance ranks associated with each subcriterion. Among three main criteria, economic subcriteria group found out to be the most important factor, where environmental subcriterion group ranked last. However, individual criterion global rankings show that waste amount generated is the fourth important criterion among all sixteen criteria, where recycling ranked seventh and emission values ranked ninth.

From the results shared above, the following conclusions can be drawn. Firstly, executives of PVC manufacturers in Turkey are aware about the importance of environmental issues. However, intense competition in the market forces the private sector to focus on costs, production times, and quality more than environmental issues. Secondly, recycling of PVC is being seen as a risky and costly approach by the manufacturers for several reasons such as, low purity of PVC waste separated [71], degradation of PVC during recycling processes [6], investment costs of bult-in recycling facilities, and additional logistics cost of supply [35]. These issues seem to be the primary concerns of executives. However, preparation of guidelines on separate collection and sorting of plastic waste and introducing regulations for this purpose by the government, as suggested in the European Strategy for Plastics in a Circular Economy [32], would especially benefit the recycling process efficiency of PVC waste, and encourage the use of recycled PVC by the manufacturers in Turkey. Low quality of PVC waste and cross contamination issues are stated as the most challenging problem by the DMs in this study. Incentives to solve this problem would certainly increase the recycling rate in manufacturers by supporting them in Turkey. Thirdly, opportunities related with the reduced emissions that can be achieved by the recycling process is not being preferred by manufacturers because of aforementioned reasons. Therefore, to increase the importance of environmental factors in strategic level decisions, introduction of cost-efficient recycling technologies and waste reduction approaches are necessary for Turkish PVC manufacturers. Also, some tax regulation differentiations or incentives can 
be regulated by the government to encourage the use of recycled raw materials instead of virgin polymers, and reducing the plastic wastes. Introduction of some legal regulations according to Operation Clean Sweep ${ }^{\circledR}$ [70] to reduce the amount of plastic spill into the environment would be a feasible incentive for companies to take some precautions throughout their value chains and organize trainings for the employees in a cost-efficient way with considerable gains for both companies and the environment. A certification scheme with external audit can be considered by the government for this purpose [32].

Results of this study would be helpful to understand the approach of PVC manufacturers to environmental issues in developing countries. This understanding can be useful to develop incentive measures in the future to increase recycling rate to contribute to circular economy model [32] being developed, especially if Turkey is going to switch to zero-waste manufacturing in 2025 [12]. Better waste collection systems and innovations in sorting and recycling technologies [74] is a vital requirement to increase the usage rate of recycled PVC. Investors can consider to build up companies specialized in this area to support recycling in Turkey if supported by proper incentives. Establishing standardization and quality certification institutions for recycled materials [74] is another requirement which creates an investment opportunity for entrepreneurs in Turkey. Setting up companies that specializes on the chemical recycling of PVC [75] also seems a good investment option in Turkey, since most recycling operations still depend on mechanical processes. Establishing a cost-effective chemical recycling service providing company promises a great potential since this method also reduces environmental effects of the process [11]. Moreover, MCGDM framework proposed in this study can be used to evaluate the priorities of PVC manufacturers in different countries to conduct cross-country comparisons to state the differences and to compare their external reasons. Nevertheless, considering the long-life span of PVC products and exponentially increasing amounts of PVC waste, it is important to increase their recycling rate to reduce their harmful effects on the environment. Therefore, it is essential to analyze and understand the factors withholding private sector from investments on recycling, and develop solution approaches to maintain a balance between protecting the environment and retaining competitive advantage in the market.

\section{Acknowledgments}

The author thanks the anonymous reviewers for their suggestions which have helped make the quality and clarity of this article better, and the editor for managing the process of the paper.

\section{Conflict of Interest}

The author declares no conflict of interest.

\section{References}

1. JAMBECK J.R., GEYER R., WILCOX C., SIEGLER T.R., PERRYMAN M., ANDRAY A., NARAYAN R., LAW K.L. Plastic waste inputs from land into the ocean. Science, 347 (6223), 768, 2015.

2. XU Z., KOLAPKAR S.S., ZINCHIK S., BAR-ZIV E., MCDONALD A.G. Comprehensive kinetic study of thermal degradation of polyvinylchloride (PVC). Polymer Degradation and Stability, 176, 1, 2020.

3. GEYER R., JAMBECK J.R., LAW K.L. Production, use, and fate of all plastics ever made. Sci. Adv., 3 (7), 2017.

4. Plastics Europe. Plastics-the Facts 2019 an Analysis of European Plastics Production, Demand and Waste Data. Available online: https:/www.plasticseurope.org/ application/files/1115/7236/4388/FINAL_web_version Plastics_the_facts2019_14102019.pdf (13 October 2020).

5. European Union Directive 2008/98/EC of European Parliament and of the Council of 19 November 2008 on Waste and Repealing Certain Directives, 2008. Available online: https://eur-lex.europa.eu/legal-content/EN/ TXT/?uri=CELEX:32008L0098 (13 October 2020).

6. SINGH N., HUI D., SINGH R., AHUJA I.P.S., FEO L., FRATERNALI F. Recycling of plastic solid waste: a state of art review and future applications. Compos. Part B Eng., 115, 409, 2017.

7. LIU Y., ZHOU C., LI F., LIU H., YANG J. Stocks and flows of polyvinyl chloride (PVC) in China: 1980-2050. Resources, Conservation and Recycling, 154, 1, 2020.

8. BREMS A., BAEYENS J., DEWIL R. Recycling and recovery of post-consumer plastic solid waste in a European context. Therm. Sci., 16, 669, 2012.

9. YE L., QI C., HONG J., MA X. Life cycle assessment of polyvinyl chloride production and its recyclability in China. J. Clean. Prod., 142, 2965, 2017.

10. CIACCI L, PASSARINI F., VASSURA I. The European PVC cycle: In-use stock and flows. Resources, Conservation and Recycling, 123, 108, 2017.

11. SADAT-SHOJAI M., BAKHSHANDEH G.R. Recycling of PVC wastes. Polym. Degrad. Stab., 96 (4), 404, 2011.

12. Pagev. Turkish PVC Industry Follow-Up Report 2017/9 Months (with year-end estimation), 2017 Available online: https://pagev.org/turkish-pvc-industry-follow-up-report2017-9-months-with-year-end-estimation-5a4254e2ae43e (13 October 2020).

13. BAUMANN H. Plastic pipes made of recycled plastic. Technology, Law and Insurance, 3, 209, 1998.

14. NAKAZAWA K., SAKAI S., KATAYAMA K., YASUI I. Life cycle analysis of environmental load from polyvinyl chloride products. J. Japan Inst. Energy, 86 (5), 339, 2007.

15. CORREA C.A., DE SANTI C.R., LECLERC A. GreenPVC with full recycled industrial waste and renewably sourced content. Journal of Cleaner Production, 229, 1397, 2019.

16. SOTAYA A., GREEN S., TURVEY G. Experimental investigation and Finite Element (FE) analysis of the load-deformation response of PVC fencing structures. Structures, 19, 424, 2019. 
17. NAJAFI V., ABDOLLAHI H. Internally plasticized PVC by four different green plasticizer compounds. European Polymer Journal, 128, 1, 2020.

18. KATAMI T., YASUHARA A., OKUDA T., SHIBAMOTO T. Formation of PCDDs, PCDFs, and coplanar PCBs from polyvinyl chloride during combustion in an incinerator. Environ. Sci. Technol., 36, 1320, 2002.

19. ZHANG R.Z., LUO Y.H., YIN R.H. Experimental study on dioxin formation in an MSW gasification-combustion process: an attempt for the simultaneous control of dioxins and nitrogen oxides. Waste Manage., 82, 292, 2018.

20. ZHOU Y., YANG N., HU S. Industrial metabolism of PVC in China: a dynamic material flow analysis. Resour. Conserv. Recy., 73, 33, 2013.

21. PIKOŃ K., CZOP M. Environmental impact of biodegradable packaging waste utilization. Pol. J. Environ. Stud, 23 (3), 969, 2014.

22. BERKUN M., ARAS E., ANILAN T. Solid waste management practices in Turkey. J Mater. Cycles Waste. Manag., 13, 305, 2011.

23. GRIGORE M.E. Methods of recycling, properties and applications of recycled thermoplastic polymers. Recycling, 2, 24, 2017.

24. CHAE Y., AN J.J. Current research trends on plastic pollution and ecological impacts on the soil ecosystem: A review. Environmental Pollution, 240, 387, 2018.

25. TURAN N.G., ÇORUH S., AKDEMİR A., ERGUN O.N. Municipal solid waste management strategies in Turkey. Waste Management, 29 (1), 465, 2009.

26. FARACA G., ASTRUP T. Plastic waste from recycling centres: Characterisation and evaluation of plastic recyclability. Waste Management, 95, 388, 2019.

27. RAGAERT K., DELVA L., VAN GEEM K. Mechanical and chemical recycling of solid plastic waste. Waste Manage., 69, 24, 2017.

28. HAMAD K., KASEEM M., DERI F. Recycling of waste from polymer materials: An overview of the recent works. Polymer Degradation and Stability, 98 (12), 2801, 2013.

29. COBAN A., ERTIS I.F., CAVDAROGLU N.A. Municipal solid waste management via multi-criteria decision making methods: A case study in Istanbul, Turkey. Journal of Cleaner Production, 180, 159, 2018.

30. SOLTANI A., HEWAGE K., REZA B., SADIQ R. Multiple stakeholders in multicriteria decision making in the context of municipal solid waste management: a review. Waste Manag., 35, 318, 2015.

31. GENEROWICZ A. Multi-criteria analysis of waste management in Szczecin. Pol. J. Environ. Stud, 23 (1), 57, 2014.

32. European Commission, A European Strategy for Plastics in a Circular Economy. Available online: https://eur-lex. europa.eu/legal-content/EN/TXT/?qid=1516265440535 \&uri=COM:2018:28:FIN (13 October 2020).

33. VALERIO O., MUTHURAI R., CODOU A. Strategies for polymer to polymer recycling from waste: Current trends and opportunities for improving the circular economy of polymers in South America. Current Opinion in Green and Sustainable Chemistry, 25, 1, 2020.

34. RAGAERT K., HUYSVELD S., VYNCKE G., HUBO S., VEELAERT L., DEWULF J., DU BOIS E. Design from recycling: A complex mixed plastic waste case study. Resources, Conservation and Recycling, 155, 1, 2020.

35. SEIKE T., ISOBE T., HARADA Y., KIM K., SHIMURA M. Analysis of the efficacy and feasibility of recycling
PVC sashes in Japan. Resources, Conservation and Recycling, 131, 41, 2018.

36. ASIF K., CHAUDHRY M.N., ASHRAF U., ALI I., ALI M. A GIS-Based multi-criteria evaluation of landfill site selection in Lahore, Pakistan. Pol. J. Environ. Stud, 29 (2), 1511,2020

37. BADGIE D., SAMAH M.A.A., MANAF L.A., MUDA A.B. Assessment of municipal solid waste composition in Malaysia: management, practice, and challenges. Pol. J. Environ. Stud, 21 (3), 539, 2012.

38. CHAE B. Developing key performance indicators for supply chain: an industry perspective. Supply Chain Management: An International Journal, 14 (6), 422, 2009.

39. MEIER H., LAGEMANN H., MORLOCK F., RATHMANN C. Key Performance Indicators for Assessing the Planning and Delivery of Industrial Services. Procedia CIRP, 11, 99, 2013.

40. KONSTA K., PLOMARITOU E. Key performance indicators (KPIs) and shipping companies performance evaluation: the case of Greek tanker shipping companies. International Journal of Business and Management, 7 (10), 142, 2012

41. CHAN A.P.C., CHAN A.P.L. Key performance indicators for measuring construction success. Benchmarking: an international journal, 11 (2), 203, 2004.

42. JOHNSON R., SOENEN L. Indicators of Successful Companies. European Management Journal, 21 (3), 364, 2003.

43. BRUYN W.C., BORODIN D., ZELTZER L., VRECKEM B.V. Key performance indicators: linking with ISA-95 and moving toward KPI-driven factory. 11th International Scientific and Practical Conference: Innovations, ICT Technologies and Their Application in Education, Borisoglebsk, Russia, 2010.

44. LINDBERG C.F., TAN S.T., YAN J.Y., STARFELT F. Key Performance Indicators Improve Industrial Performance. Energy Procedia, 75,1785, 2015.

45. AMRINA E., YUSOF S.M. Key performance indicators for sustainable manufacturing evaluation in automotive companies. IEEE International Conference on Industrial Engineering and Engineering Management, Singapore, 1093, 2011.

46. AMRINA E., VILSI A.L. Key performance indicators for sustainable manufacturing evaluation in cement industry. Procedia CIRP, 26, 19, 2015.

47. SIKDAR S.K. Sustainable development and sustainability metrics. AIChE J., 49, 1928, 2003.

48. JASCH C. Environmental performance evaluation and indicators. Journal of Cleaner Production, 8 (1), 79, 2000.

49. YE L., QI C., HONG J., MA X. Life cycle assessment of polyvinyl chloride production and its recyclability in China. Journal of Cleaner Production, 142 (4), 2965, 2017.

50. INTERNATIONAL ORGANIZATION FOR STANDARDIZATION. Environmental Management: Life Cycle Assessment; Principles and Framework. ISO, 2006.

51. XIONG J., ZHU J., HE Y., REN S., HUANG W., LU F. The application of life cycle assessment for the optimization of pipe materials of building water supply and drainage system. Sustainable Cities and Society, 60, 102267, 2020.

52. STICHNOTHE H., AZAPAGIC A. Life cycle assessment of recycling PVC window frames. Resources, Conservation and Recycling, 71, 40, 2013. 
53. SHEN L., WORRELL E., PATEL M.K. Open-loop recycling: a LCA case study of PET bottle-to-fibre recycling. Resources, Conservation and Recycling, 55,34, 2010.

54. SALAZAR J. Life cycle assessment (LCA) of windows and window materials. In Eco-efficient Construction and Building Materials, Pacheco-Torgal F., Cabeza L.F., Labrincha J., de Magalhães A., Eds., Woodhead Publishing, pp. 502, 2014.

55. CHERUBINI F., BARGIGLI S., ULGIATI S. Life cycle assessment (LCA) of waste management strategies: Landfilling, sorting plant and incineration. Energy, 34 (12), 2116, 2009.

56. DING J., CHEN W., WANG W. Production and carbon emission reduction decisions for remanufacturing firms under carbon tax and take-back legislation. Computers \& Industrial Engineering, 143, 106419, 2020.

57. TUOMI K. The role of the investment climate and tax incentives in the foreign direct investment decision: evidence from South Africa. Journal of African Business, 12 (1), 133, 2011.

58. ROY P., DUTTA A. Life cycle assessment (LCA) in municipal waste management decision making. In Plastics Design Library, Al-Salem S.M., Eds., William Andrew Publishing, pp. 377, 2019.

59. NEELY A., GREGORY M., PLATTS K. "Performance measurement system design: a literature review and research agenda. International journal of operations \& production management, 15 (4), 80, 1995.

60. NAVARRE C., SCHAAN J-L. Design of project management systems from top management's perspective. Project Management Journal, 21 (2), 19, 1990.

61. BAÇ U., ERKAN T.E. A model to evaluate supply chain performance and flexibility. African Journal of Business Management, 5 (11), 4263, 2011.

62. RAO P., LA O' CATILLO O., INTAL P.S., SAJID A. Environmental indicators for small and medium enterprises in the Philippines: An empirical research. Journal of Cleaner Production, 14 (5), 505, 2006.

63. SHEFRIN H., STATMAN M. Making sense of beta, size and book-to-market. The Journal of Portfolio Management, 21 (2), 26, 1995

64. HILLERMAN T., SOUZA J.C.F., REIS A.C.B., CARVALHO R.N. Applying clustering and AHP methods for evaluating suspect healthcare claims. Journal of Computational Science, 19, 97, 2017.

65. LIMA E., GORSKI E., LOURES E.F.L., SANTOS E.A.P., DESCHAMPS F. Applying machine learning to AHP Multicriteria Decision Making Method to assets prioritization in the context of industrial maintance 4.0. IFAC PapersOnLine, 52 (13), 2152, 2019.

66. SHAKIBA S., ASGHARI O., KHAH N.K.F. A combined approach based on MAF analysis and AHP method to fault detection mapping: A case study from a gas field, southwest of Iran. Journal of Applied Geophysics, 148, 8, 2018.

67. BAÇ, U. An integrated SWARA-WASPAS group decision making framework to evaluate smart card systems for public transportation. Mathematics, 8 (10), 1723, 2020.

68. CHIU W.Y., LEE Y.D., LIN T.Y. Performance evaluation criteria for personal trainers: An Analytical Hierarchy Process approach. Social Behavior and Personality, 38 (7), 895, 2010.

69. SAATY T.L. The Analytic Hierarchy Process, McGrawHill: New York, United States, 1980.

70. Plastics Europe. Operation Clean Sweep ${ }^{\circledR}$, Progress Report, 2019. Available online: https://www.plasticseurope. org/download_file/force/4156/181 (13 October 2020).

71. AYDIN N. Review of municipal solid waste management in Turkey with a particular focus on recycling of plastics. Energy Procedia, 113, 111, 2017.

72. European Commission. Development of guidance on Extended Producer Responsibility (EPR) final report. Available online: https://ec.europa.eu/environment/ archives/waste/eu_guidance/pdf/Guidance $\% 20$ on $\% 20$ EPR\%20-\%20Final\%20Report.pdf (13 October 2020).

73. PAZIENZA P., DE LUCIA C. For a new plastics economy in agriculture: Policy reflections on the EU strategy from a local perspective. Journal of Cleaner Production, 253, 119844, 2020.

74. Plastics Europe. The Circular Economy for Plastics A European Overview. Available online: https://www. plasticseurope.org/download_file/force/3259/181 October 2020)

75. Plastics Europe. Plastics 2030: PlasticsEurope's Voluntary Commitment to increasing circularity and resource efficiency. Available online: https://www.plasticseurope. org/download_file/view/491/603 (13 October 2020). 